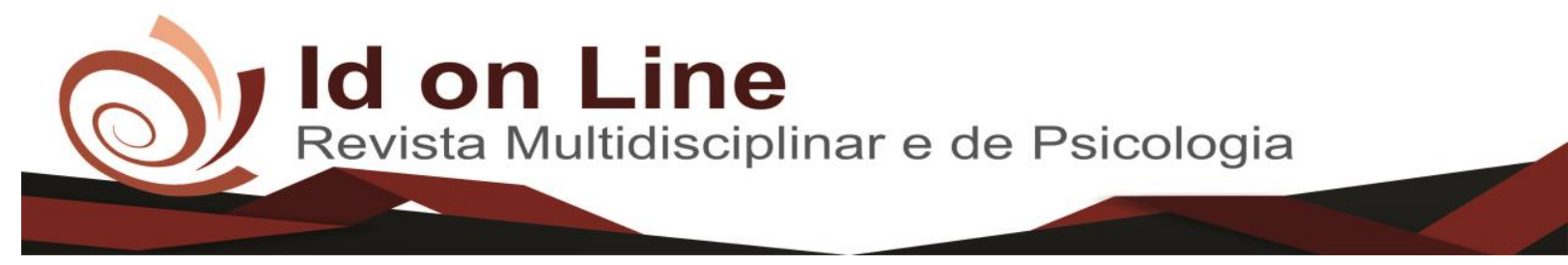

Artigo de Revisão

\title{
Orientação Profissional na Adolescência: Uma Revisão Sistemática
}

Maria Nayara Bezerra Limal ${ }^{\text {; Thércia Lucena Grangeiro Maranhão }}{ }^{2}$

Resumo: O presente artigo tem como objetivos compreender o desenvolvimento humano na fase da adolescência e tratar sobre as influências que permeiam a escolha profissional desse sujeito. Para tanto, observa-se o que os estudos atuais comentam sobre a adolescência em si e sugere-se como a Orientação Profissional pode contribuir para o desenrolar dessas escolhas, como uma ferramenta de auxílio ao sujeito. Esta pesquisa foi delineada por meio da revisão sistemática por metassintese da literatura dos textos e estudos que abordam o tema, que foram selecionados entre o período de 2012 e 2016, retirados das bases de dados do PubMed, Scielo e PepSIC. Percebeuse através deste trabalho que os fatores sociais, culturais, familiar e econômico influenciam tanto no desenvolvimento da adolescência quanto no momento da escolha de sua profissão.

Palavras-chave: Orientação profissional, Escolha profissional e Adolescência.

\section{Vocational Guidance in Adolescence: A Systematic Review}

\begin{abstract}
The present article aims to understand human development in adolescence and to deal with the influences that permeate the professional choice of this subject. Therefore, it is observed that the current studies comment on adolescence itself and it is suggested how Professional Guidance can contribute to the development of these choices, as a support tool to the subject. This research was delineated through the systematic review by metaassintese of the literature of the texts studies that approach the theme, which were selected between the period of 2012 and 2016, from the PubMed, Scielo and PepSIC databases. It can be seen from this work that social, cultural, family and economic factors influence both the development of adolescence and the moment of choosing their profession.
\end{abstract}

Keyowords: Professional Orientation; PProfessional choice; Adolescenc.

\footnotetext{
${ }^{1}$ Psicóloga CRP-11/11242 . nayarab.lima@ hotmail.com.

${ }^{2}$ Psicologa. Professora da UNILEÃO. Mestra em Ciências da Saúde pela Faculdade de Medicina do ABC.

Coordenadora da ABRH-CE Núcleo Cariri. E-mail:therciapsicologa@gmail.com
}

158 Id on Line Rev. Mult. Psic. V.12, N. 42, p. 158-186, 2018 - ISSN 1981-1179 


\section{Introdução}

O presente trabalho trata de uma revisão sistemática acerca da adolescência e dos fatores que influenciam a escolha profissional, perpassada pela maneira como a orientação profissional pode auxiliar nesse momento de escolha. (BECKER, BOBATO e SCHULZ, 2012; MAGALHÃES, ALVARENGA e TEIXEIRA, 2012).

A Orientação Profissional como um processo a ser realizado junto ao adolescente propicia informações que auxiliam no desenvolvimento do sujeito a partir de sua construção pessoal e profissional. Em suma, faz com que o sujeito identifique seus conhecimentos para que posteriormente aplique-os de maneira prática, assumindo uma postura de enfrentamento em diversas situações (DUARTE, 2013).

No que se refere a adolescência esta é um período no qual o sujeito busca autoconhecimento, enfrenta diversas situações, e, para tanto, faz escolhas importantes. Tais ações influenciam de maneira direta ou indireta na vida do sujeito. Assim, se torna necessário buscar compreender como esta fase do desenvolvimento se constrói. Nesse ínterim uma das escolhas mais difíceis que o indivíduo que vivencia esta fase tem que fazer é a de escolha profissional.

Decidir qual profissão exercer no futuro é algo bastante complexo, já que esta decisão não é algo que depende unicamente do adolescente. Tal questão, tão importante para a própria constituição do sujeito, sofre influências de fatores sociais, familiares, econômicos e educacionais. O processo de Orientação Profissional pode auxiliar o sujeito ao facilitar esse processo de escolha, no qual o adolescente passará por um período de reflexão, buscando identificar seus gostos e sua personalidade, para posteriormente efetivar a escolha profissional.

Tendo em vista que o grupo familiar, os amigos, a sociedade, as tecnologias e a economia são alguns dos fatores que influenciam o adolescente no momento em que este exerce sua escolha profissional, este trabalho tem como questionamento norteador compreender quais os fatores que influenciam a escolha profissional?

Tendo como objetivo principal compreender o desenvolvimento humano na fase da adolescência, e como objetivos específicos estudar sobre as influências que permeiam a escolha profissional desse sujeito na adolescência ; Compreender de que modo a Orientação Profissional pode auxiliar o adolescente em sua escolha profissional. 
Foram utilizados como fontes de pesquisa as bases de dados do Google acadêmico, Scielo e PepSIC, publicados entre os anos de 2012 a 2016, onde foram utilizadas as palavraschave: Orientação profissional, Escolha profissional e Adolescência.

O interesse nessa temática surgiu durante as disciplinas do curso de graduação em psicologia, posteriormente em experiências vividas no campo de estágio obrigatório com Ênfase em Gestão, pois por um ano houve contato com estudantes do ensino médio, podendose observar conflitos que estes enfrentavam no tocante a escolha profissional.

\section{Referencial Teórico}

\section{O Ser adolescente}

Historicamente, até o início do século $\mathrm{XV}$, a fase da adolescência não era discutida ou reconhecida perante a sociedade, eram considerados apenas os grupos das crianças e o dos adultos. As primeiras discussões referentes a esta fase do desenvolvimento humano ocorreram ainda na metade deste mesmo século, no entanto foi apenas no século XX que adolescência foi reconhecida como um período significativo para a construção da vida do sujeito (SENNA e DESSEN, 2012; VELHO, QUINTANA e ROSSI 2014).

Nas últimas décadas diversas transformações surgem no Brasil e no mundo, graças à globalização que acelerou e facilitou o processo do compartilhamento de informações, afetando os modelos vigentes sociais, familiares, políticos e econômicos. As transformações ocorridas no núcleo familiar são as que mais inquietam os pesquisadores, estes apontam o fato de tais mudanças estejam influenciando o desenvolvimento da adolescência, pois estes jovens, ao estarem inseridos em diversos grupos, possuem um contato com uma gama variada de situações relacionadas a modelos familiares, escolha profissional, modelos de personalidades e estilos de vida (SENNA e DESSEN, 2012; PAPALIA e FELDMAN, 2013; VELHO, QUINTANA e ROSSI 2014).

A adolescência é reconhecida como um momento de significativas transformações no desenvolvimento humano, causando, além das evidentes mudanças biológicas e anatômicas caracterizadas pela puberdade e o surto de crescimento - as mudanças sexuais, emocionais, cognitivas, sociais e culturais, promovendo um significativo desenvolvimento do self. Neste 
período o jovem vivencia uma inconstância em sua vida, isto é, diversos momentos que lhe causam angustias. A durabilidade desta fase está sofrendo influencias, pois, está se tornando muito extensa, que descreve a passagem da vida infantil para a adulta (PAPALIA e FELDMAN, 2013; QUIROGA e VITALLE, 2013; SANTOS, LUNA e BARDAGI, 2014).

Uma das formas de representação da adolescência é a trazida por Velho, Quintana e Rossi (2014) que acreditam que esta fase sofre influências sociais, culturais e econômicas, os quais jovens de classes mais privilegiadas passam pela adolescência, e os de menor poder aquisitivo vivenciam a passagem apenas da puberdade. Esta forma de representação está mais voltada para questões relacionadas ao consumo.

Ao se referir à idade necessária para adentrar e finalizar a adolescência ainda não existe um consenso entre os estudiosos. Berger (2013) traz como início da adolescência 10 anos e o final aos dos 19 ou 20 anos, já Papalia e Feldman (2013) consideram que a adolescência se inicia aos 11 anos e finaliza-se por volta dos 19 ou 20 anos, tornando assim praticamente impossível determinar ao certo a faixa etária exata em que a fase da adolescência se desenvolve. A idade que será considerada por este estudo referente ao início e término da adolescência é a trazida pelo Estatuto da Criança e do Adolescente onde no Artigo $2^{\circ}$ é definida a idade de doze a dezoito anos (DIGIÁCOMO e DIGIÁCOMO, 2013).

Mas o marco inicial da fase da adolescência são as mudanças biológicas, caracterizadas pela puberdade, que perdura em média de 3 a 4 anos. Anteriormente, em países subdesenvolvidos, as inserções dessas mudanças ocorriam através de eventos ritualísticos, e, atualmente, os adolescentes desses mesmos países passam pelo mesmo processo dos adolescentes de países mais desenvolvidos, onde ocorre um surto de crescimento físico, as mudanças hormonais e o desenvolvimento sexual, predefinindo os papeis de gênero (BERGER, 2013; PAPALIA e FELDMAN, 2013; VELHO, QUINTANA e ROSSI 2014).

Com relação ao desenvolvimento cognitivo na adolescência, se notam avanços significativos relacionados a capacidade de raciocínio do sujeito, pois este passa a elaborar com maior velocidade o processamento de informações, possibilitando uma maior compreensão a respeito das emoções e sentimentos dos sujeitos que estão a sua volta, fazendo com que este identifique de modo mais claro as expectativas que a sociedade tem sobre ele. $\mathrm{O}$ adolescente consegue desenvolver diversas atividades em um mesmo período de tempo, mas não necessariamente aprofundando-se em alguma, absorvendo uma gama de informações, agregando-as aos conhecimentos existentes, enriquecendo seu vocabulário tanto escrito como 
oral, encaixando-se na fase do pensamento operacional formal, conseguindo compreender problemas tanto de uma forma abstrata quanto de forma real, - em algumas situações - até desenvolvendo um julgamento moral, enriquecendo e explorando assim suas habilidades (BERGER, 2013; PAPALIA e FELDMAN, 2013; FERRONHA et al. 2014; SANTOS, LUNA e BARDAGI, 2014; VELHO, QUINTANA e ROSSI 2014).

A adolescência é socialmente formada e, atualmente, foi denominada de Geração Z. Esta nomenclatura expõe uma das formas de representação desta fase do desenvolvimento. Esta foi desenvolvida sobre os alicerces da sociedade contemporânea atual, que possui o imediatismo e as relações frágeis e rápidas como algumas de suas características mais marcantes e que influenciam diretamente na constituição do comportamento do sujeito. Moldam-se, por tanto, vínculos baseados em consumo, rapidez e imediatismo (PAPALIA e FELDMAN, 2013; SANTOS, LUNA e BARDAGI, 2014).

A vivencia da adolescência busca desenvolver uma ligação entre seus sentimentos, reflexões e ações, para constituir e compreender sua identidade, assim este sujeito passa a representar diversas funções e papeis. Erik Erikson (1968), um estudioso do desenvolvimento da adolescência, traz a ideia de que para o sujeito tornar-se um adulto equilibrado este deve passar por um período de construção da identidade. O sujeito vivencia uma confusão de papeis, até o momento em que consiga desenvolver um status permanente, que é chamado de realização da identidade, o qual aquilo que foi aprendido na fase infantil passa a ser visto e compreendido de uma nova forma, o sujeito cria uma ideia do que deseja tornar-se, e nesse momento ele deve aceitar e rejeitar alguns modelos estabelecidos socialmente. Sendo assim, a construção da identidade não depende exclusivamente do sujeito, já que esta sofre influências culturais, sociais e familiares (BERGER, 2013; PAPALIA e FELDMAN, 2013)

A adolescência sempre foi vista como uma fase que sofre fortes influências dos adultos que estão em volta do sujeito. Levanta-se a ideia que o modelo de sociedade em que os pais, ou os adultos vivenciaram não é tão distinta da sociedade atual, já que os valores são perpassados de modo geracional, no entanto cada geração produz um ideal diferente. Nesse momento de transição em que o sujeito encontra-se na fase da adolescência, os pais, com receio de que os ideais familiares sejam extintos, tentam transmitir os valores, as crenças e os costumes familiares para seus filhos, no entanto o adolescente busca sua identidade e desenvolver sua autonomia, tentando livrar-se das amarras parentais, enfrentando ou negando as figuras de autoridade, tornando-se necessário desenvolver um equilíbrio entre a relação de afeto com a 
família e a sua autonomia pessoal (MAGALHÃES, ALVARENGA e TEIXEIRA, 2012; BERGER, 2013; PAPALIA e FELDMAN, 2013; VELHO, QUINTANA e ROSSI 2014).

Surge neste momento uma relação conflituosa entre pais e filhos, afetando bruscamente a quantidade de tempo compartilhado em conjunto pela família, que varia de acordo com a sociedade que o sujeito está inserido. Tal situação modifica, também, as atitudes e comportamentos dos pais. No entanto alguns adolescentes - com mais segurança em relação a eles mesmos - conseguem passar por este período de busca pelo autoconhecimento e manterem relações saudáveis e resistentes com seus genitores, evidenciando que uma ligação saudável entre pais e filhos auxilia, de maneira positiva, na constituição da identidade (MAGALHÃES, ALVARENGA e TEIXEIRA, 2012; BERGER, 2013; PAPALIA e FELDMAN, 2013; VELHO, QUINTANA e ROSSI 2014).

É de suma importância compreender também o grupo de amigos, já que ele está presente desde a infância e na adolescência este grupo torna-se indispensável. Este se torna uma das peças fundamentais para o desenvolvimento dessa fase, responsável por desenvolver uma conexão entre o grupo familiar e a sociedade, na qual o adolescente buscará relacionar-se com seus pares, passando uma quantidade de tempo maior com o grupo de pessoas com as mesmas características que ele, buscando nesse conjunto sua identidade, reconhecimento, habilidades, apoio social e valores, proporcionando uma maior confiança referente a seus atos, que podem repercutir de maneira positiva ou negativa (BERGER, 2013; PAPALIA e FELDMAN, 2013; VELHO, QUINTANA e ROSSI 2014).

É de suma importância salientar que tanto o núcleo familiar quanto o grupo de amigos funcionam como um alicerce para o adolescente, estimulando e encorajando este sujeito a enfrentar os desafios ((MAGALHÃES, ALVARENGA e TEIXEIRA, 2012).

\section{As influências e a escolha profissional}

Para que o sujeito se torne um adulto responsável e apto a fazer suas próprias escolhas e assim conduzir sua própria vida, é necessário que na adolescência o indivíduo tenha que tomar várias decisões e fazer diversas escolhas. Uma destas escolhas refere-se a carreira profissional. Mesmo que esta não seja a última escolha referente ao mundo do trabalho que o adolescente terá que fazer é vista como a escolha que inicializará o mesmo no mundo profissional, causadora 
de uma crescente indecisão entre os jovens, já que esta sofre diversas influências sociais, familiares, econômicas e pessoais (COLOMBO e PRATI, 2014; JUNQUEIRA e MELOSILVA, 2014; BARROS, NORONHA e AMBIE, 2015).

A obtenção da identidade e maturidade para a carreira são vistas como algumas das características principais no momento da escolha profissional, sendo necessário que o indivíduo desenvolva uma postura que esteja apta a possibilidade de compreender e lidar com as decisões que este deve fazer referente a escolha profissional. $\mathrm{O}$ meio em que o adolescente está inserido influencia significativamente na construção da identidade profissional, que está intimamente interligada a constituição da identidade pessoal, em consonância com a maturidade profissional proporcionará mais subsídios que irão auxiliar na realização de um profissional realizado. As instituições, tecnologias e organizações oferecem subsídios ao adolescente que podem intervir nesse processo de decisão profissional. É de suma importância que o adolescente esteja com sua identidade e sua maturidade profissional formadas, já que estão relacionadas com a preferência ou não por uma profissão, para evitar que este tome uma decisão equivocada, fundamentando sua escolha apenas naquilo que é conveniente e cômodo (COLOMBO e PRATI, 2014; JUNQUEIRA e MELO-SILVA, 2014).

O núcleo familiar, a sociedade, a cultura, as tecnologias, os pares e a economia são alguns dos principais fatores que mais influenciam positivamente ou negativamente a efetivação da escolha profissional na adolescência (BECKER, BOBATO e SCHULZ, 2012; MAGALHÃES, ALVARENGA e TEIXEIRA, 2012). Todas as instituições citadas acima estão inseridas em um meio social, replicando assim tudo o que é produzido neste contexto, funcionando deste modo como uma forma de pilares para a sociedade. (NEIVA, 2013).

De acordo com Duarte (2013) as transformações ocorridas na sociedade atual como a taxa de desemprego, a baixa qualidade de vida, as transições do ambiente escolar para o mercado de trabalho influenciam significativamente nas vidas de uma grande parte dos habitantes.

Segundo Valore e Cavallet (2012) O fator financeiro comumente se sobressai influenciando e limitando a escolha profissional de adolescentes oriundos de classes econômicas menos favorecidas, já que o adolescente que vivencia esta realidade tem que pautar suas escolhas visando o peso econômico que elas irão gerar, optando as vezes por uma profissão que se adeque melhor a suas condições. 
As mudanças na sociedade e na economia são influenciadas pelo surgimento de novas tecnologias, que como resultado criam e extinguem diversas profissões, modificando significativamente o fluxo do mercado de trabalho, exigindo do indivíduo uma flexibilidade, reflexões e modificações ao longo do seu percurso profissional (NEIVA, 2013).

Como consequência das mudanças ocorridas no contexto social atual os adolescentes enfrentam problemas no tocante a elencar aquilo que é mais relevante, não conseguindo classificar seus desejos, fazendo com que estes tenham dificuldade em visualizar um futuro profissional. As transformações citadas acima corroboram para o desenvolvimento de uma relutância por parte do adolescente referente a algo que demande um longo período de tempo, acarretando em um distanciamento entre o ambiente escolar e o adolescente (SANTOS, LUNA e BARDAGI, 2014).

A família é o primeiro grupo social em que o sujeito é inserido, influenciando na formação, construção da identidade profissional e momento em que o adolescente deve fazer a escolha profissional, podendo interferir nas questões referentes ao desempenho acadêmico e profissional. A família pode influenciar de maneira mais diretiva, que pode ser exemplificado quando os pais deliberam acerca da escolha, ou de modo mais indireto quando as condições sociais, culturais ou financeiras da família influenciam na escolha. Para que o adolescente construa de maneira sólida o processo da sua escolha profissional a autonomia, independência das figuras parentais atrelado a uma relação segura de apego com seus pais são características de suma relevância que devem estar presentes nesse processo (MAGALHÃES, ALVARENGA e TEIXEIRA, 2012; DIAS e SÁ, 2014). Tais questões podem gerar um grande sofrimento ao sujeito que vivencia esse momento de escolha, tendo em vista que a pressão sofrida gerada pela família ou por algum outro fator interfere diretamente nesta escolha, ocasionando assim, em algo danoso e prejudicial para o adolescente.

O círculo de amizades possibilita o compartilhamento de anseios entre adolescentes, permitindo que ocorra uma troca de conhecimentos referente a realidade social e a escolha profissional desses sujeitos. Em alguns casos pode dificultar a escolha do indivíduo, já que o mesmo possa vir a ter algum receio referente a escolha profissional ligada a possível exclusão do seu grupo social se esta escolha não se adequar a dos demais (NEIVA, 2013).

É possível que as ideias dos amigos interfiram na escolha do adolescente, já que nesta fase do desenvolvimento o indivíduo é bastante propenso a opinião daqueles a sua volta (ANDRADE et al. 2016). 
De acordo com Oliveira e Neiva (2013) surgem na atualidade modificações nas esferas socioeconômicas e políticas que impactam no mundo do trabalho no Brasil, deixando em evidente a existência que há uma relação empobrecida entre o mundo do trabalho e a educação fornecida nas instituições de ensino.

É esperado que no contexto escolar sejam tratadas questões como a esfera do trabalho e a formação da cidadania, no entanto, esta instituição está fazendo o caminho inverso, deixando a orientação profissional em um segundo plano, não desenvolvendo uma relação de proximidade entre ambas (FALEIROS e LEHMAN, 2013)

As instituições de ensino desempenham um papel importante no tocante a escolha profissional, já que são a partir das disciplinas ministradas em sala que o adolescente vai descobrir com o que mais se identifica, e em quais se sobressai. O professor nesse momento exerce uma figura de significativa relevância, pois este profissional traz para dentro do ambiente de classe informações ligadas ao mundo do trabalho, além de que a relação desse adulto com sua profissão, e com o aluno interferem na escolha profissional (NEIVA, 2013).

Segundo Valore e Cavallet (2012) as escolas poderiam aderir ao seu quadro de disciplinas uma que tratasse das questões do mundo do trabalho, no intuito de estabelecer uma relação mais clara entre educação e trabalho, visando facilitar o processo de escolha.

Nesse momento pelo qual o adolescente está passando é importante compreender que as influências internas e externas existem e o adolescente deve repensar sobre tais influências e identificar quais contribuem de maneira positiva para essa escolha, desempenhando um papel crítico e de autonomia (BECKER, BOBATO e SCHULZ, 2012; JUNQUEIRA e MELOSILVA, 2014).

Conhecer a si próprio é relevante para o processo de escolha profissional, quando o indivíduo compreende quem é, o que gosta e o que deseja ser, ele obterá a possibilidade de fazer uma escolha mais consciente a respeito da sua profissão (BECKER, BOBATO e SCHULZ, 2012).

\section{A Orientação profissional como ferramenta de auxílio nesse momento de escolha}

O estudo da orientação profissional na psicologia se divide em dois períodos históricos, tendo como primeiro momento entre os anos 1900 a 1950 que tem como enfoque o uso da 
psicométrica, na qual Frank Parsons desenvolve suas ideias, deixando assim certa herança histórica que auxiliou na identificação das mudanças que atualmente são necessárias para que possa ser desenvolvido um trabalho relevante em orientação profissional. O segundo momento teve início por volta de 1950 que se estende até atualidade, onde surgiram novas compreensões referentes a escolha profissional, no intuito de conseguir desenvolver um norteamento para a realidade. Estabelecer uma relação entre a teoria e a prática, no intuito de desenvolver um bem grupal, sendo importante salientar que a partir do momento em que o orientador não deve cristalizar-se nessas ideias no processo de orientação profissional, visando não prejudicar o processo em desenvolvimento, se isto ocorrer estará se desenvolvendo um pensamento retrógrado e determinista, sendo assim, deve-se ter em mente a ideia de que estas podem se modificar (DUARTE, 2013; ANDRADE et al. 2016).

No século XX, o advento das duas Guerras Mundiais proporcionou grandes mudanças sociais que colaboraram para a atuação, o desenvolvimento e o crescimento da Orientação Profissional. Na metade deste mesmo século, surgiram a Teoria Centrada no Cliente, de Carl Roger, a Teoria Do Desenvolvimento Vocacional, de Ginzberg, e a Teoria Do Desenvolvimento Vocacional, de Donald Super, que trouxeram uma nova visão referente ao momento da escolha de uma profissão, focando no autoconhecimento e no desenvolvimento de carreiras, baseandose no conceito de que o sujeito pode desempenhar diversas atividades e funções (MANAIA et al. 2013; ANDRADE et al. 2016).

A busca pela compreensão da aplicabilidade da Orientação Profissional no século XXI requer uma postura diferente da adotada no século passado, sendo necessário levar em consideração as mudanças sociais, políticas, econômicas e culturais ocorridas que influenciaram fortemente nas mudanças sofridas na Orientação Profissional (GUICHARD, 2012).

O homem vive em uma sociedade onde pressupor o que está por vir está se tornando cada vez mais difícil. Buscar e definir o lugar certo não é mais possível, pois a expectativa que se têm é que o sujeito seja capaz, com o auxílio da Orientação Profissional, de estar apto a se adequar as mudanças e oportunidades, produzindo e sendo produto do seu meio, já que o mesmo agora é visto como responsável pelo seu desempenho profissional ou pessoal (GUICHARD, 2012; OLIVEIRA, MELO-SILVA e COLETA, 2012).

A orientação profissional atualmente não se limita apenas a auxiliar no momento da escolha de uma profissão, esta busca em consonância com aquele que participa desse processo 
desenvolver processo de construção de vida, atrelada ao trabalho, já que é cobrada pela sociedade que o indivíduo possa imprimir respostas referente ao trabalho e economia não só apenas no ambiente de trabalho (DUARTE, 2013)

Os profissionais de Psicologia que estudam a Orientação Profissional dedicam-se a pensar na relação que existe entre as características que compõem o interesse profissional e a cognição, sendo exigido destes uma postura dinâmica, que venha a possibilitar momentos e ações de intervenção no desenvolvimento pessoal (NERY e RUEDA, 2013).

No ambiente educacional a Orientação Profissional pode atuar através de uma ótica que visa promover o bem-estar do adolescente, auxiliando na relação com aqueles a sua volta, tanto como preparando este indivíduo para exercer uma postura ativa, modificando o meio em que vive, oferecendo subsídios para que esse adolescente possa vencer os empecilhos existentes nesse caminho (BARBOSA e LAMAS, 2012).

O orientador profissional que está inserido no ambiente escolar tem como uma de suas funções discutir com os adolescentes respeito da opinião dos mesmos referente ao mundo do trabalho, no intuito de desconstruir pressupostos errôneos construídos introjetados pela sociedade e temas vistos como tabus no mercado de trabalho (BARBOSA e LAMAS, 2012).

Tendo como propósito facilitar o processo da escolha de uma carreira, o orientador profissional possui o intuito de ajudar o adolescente a perceber suas predileções, exercer uma retrospectiva referente a história de vida do sujeito e compreender o fluxo atual do mercado de trabalho, visando elencar objetivos que melhor se adequem a realidade do sujeito. Nesse momento é importante que o profissional busque conhecer o núcleo familiar em que o adolescente está inserido, para assim compreender como ocorre a relação do mesmo com seus pais, tendo em vista que estes influenciam na escolha profissional (BECKER, BOBATO e SCHULZ, 2012; MAGALHÃES, ALVARENGA e TEIXEIRA, 2012).

A pessoa que irá usufruir do processo de orientação profissional espera que este profissional possa oferecer uma prévia referente a seu futuro, no entanto, é interessante que o orientador consiga fazer com que o orientando possa identificar que existe esperança ao longo dessa jornada (DUARTE, 2013).

O adolescente se encontra confuso nesse processo de mudanças e com diversas dúvidas referentes a escolha profissional. A orientação profissional, que pode conduzir e facilitar o processo da escolha, no qual o sujeito refletiria sobre sua trajetória profissional, onde seriam trabalhadas e desenvolvidas questões referentes as preferências e interesses profissionais, 
compreendendo o fluxo do mercado de trabalho e estabelecendo metas que melhor se adequem a sua realidade (BECKER, BOBATO e SCHULZ, 2012; NEIVA, 2013;).

\section{Metodologia}

O presente estudo se propõe como de uma revisão sistemática por metassíntese da literatura dos textos e estudos que abordam o tema. Foram selecionados artigos publicados entre os anos de 2012 a 2016 para este estudo. Trata-se, portanto, de um tipo de investigação focada em uma questão bem definida, que visa identificar, selecionar, avaliar e sintetizar as evidências relevantes disponíveis. (GALVÃO, PEREIRA, 2014). Esta modalidade de pesquisa tem cunho bibliográfico e se realiza por meio da revisão de resultados de pesquisas, objetivando tecer articulações para propor um novo conhecimento. (ANDRADE et al. 2016).

Segundo Galvão e Pereira (2014) os métodos para elaboração de revisões sistemáticas preveem: (1) elaboração da pergunta de pesquisa; (2) busca na literatura; (3) seleção dos artigos; (4) extração dos dados; (5) avaliação da qualidade metodológica; (6) síntese dos dados (metassíntese); (7) avaliação da qualidade das evidências; e (8) redação e publicação dos resultados.

Para que uma revisão sistemática seja por metassíntese, Oiliveira et al (2015) elenca alguns requisitos, escolha de um objetivo, delimitação das fontes que serão usadas para fazer a pesquisa, escolha das obras que serão utilizadas e formação da amostra.

A pergunta de pesquisa utilizada no presente estudo foi: quais são os fatores que influenciam na escolha profissional, e de que modo a Orientação Profissional pode auxiliar o adolescente nesse processo?

Para o embasamento desse trabalho, utilizando os artigos sobre o Desenvolvimento humano na fase da adolescência e Orientação Profissional, inicialmente fez-se uma seleção pelos títulos e resumos que contivessem as palavras-chaves: escolha profissional, orientação profissional e adolescência. A escolha dos bancos de dados eletrônicos ocorreu através daqueles que são mais acessados e conhecidos no Brasil.

Foram utilizados como fonte de pesquisa para este trabalho o Scielo, PepSIC, PubMed.

Primeiramente, o Scielo - Scientific Electronic Library Online, que se trata uma base de dados virtual desenvolvida pela FAPESP - Fundação de Amparo à Pesquisa de São Paulo. Atua 
em parceria com o BIREME - Centro Latino americano e do Caribe de Informação em Ciências da Saúde. Eles abrigam periódicos científicos brasileiros de alta qualidade, segundo o CNPQ Conselho Nacional de Desenvolvimento Científico e Tecnológico. Possuem uma metodologia semelhante de armazenamento da informação científica, em formato eletrônico.

A segunda plataforma de pesquisa de artigos fora o PepSIC - O portal de Periódicos Eletrônicos de Psicologia - é uma fonte da Biblioteca Virtual em Saúde - Psicologia da União Latino-Americana de Entidades de Psicologia (BVS-Psi ULAPSI) e fruto da parceria entre Fórum de Entidades Nacionais da Psicologia Brasileira (FENPB), Biblioteca Dante Moreira Leite do Instituto de Psicologia da Universidade de São Paulo (IP/USP) e do Centro Latino Americano e do Caribe de Informação em Ciências da Saúde - BIREME, que cedeu a metodologia - Scientific Electronic Library Online (SciELO) - modelo de publicação eletrônica de periódicos para países em desenvolvimento. O PubMed é uma outra base de dados utilizada para artigos científicos, que conta com mais de 17 milhões de artigos. É coordenada pela Biblioteca Nacional de Medicina dos Estados Unidos da América (National Library of Medicine). Trata-se de uma versão gratuita da Medline (Medical Literature Analysis and Retrieval System Online), uma base de dados da Biblioteca Nacional de Medicina americana US National Library of Medicine's. Abriga mais de 18 milhões de títulos de jornais científicos, com uma maior concentração em biomedicina, contendo ainda artigos sobre enfermagem, odontologia, veterinária, psicologia, dentre outros.

O objetivo do PePSIC é contribuir para a visibilidade do conhecimento psicológico e científico gerado nos países da América Latina, a partir da publicação de revistas científicas em acesso aberto. Ainda buscou-se mais aparato teórico para a elaboração deste trabalho, na plataforma Google Acadêmico, pois esta se mostrou uma fonte viável para busca de: artigos, teses, livros, resumos e entre outros meios. Ao todo foram utilizados cerca de 25 textos das mencionadas fontes.

Os critérios de inclusão utilizados foram os seguintes: a) artigos completos e originais; b) revisões de literatura, estudos transversais, pesquisa de campo exploratória e estudos de coorte prospectivos e retrospectivos; c) artigos em língua portuguesa; d) Estudos à partir de 2012.

Critérios de exclusão: a) estudos feitos com animais; b) estudos anteriores a 2012; c) editoriais e cartas ao editor; d) relatos de casos, séries de casos, de caso-controle; e) estudos de revisão que tenham dado ênfase a outros assuntos. 
Neste estudo, a análise do conteúdo, foi feita inicialmente por títulos e/ou frases nos artigos. Foram também consideradas as citações nos textos, porque representam uma escolha dos autores quando da fundamentação dos seus discursos.

Após a escolha dos artigos, foi estabelecida uma forma de categorizar os artigos de acordo com seu conteúdo, para assim dar um sentido ao material, agrupando-os por semelhança dos principais assuntos tratados dentro da abordagem e da proposta desse estudo (BARDIN, 2002). Conforme recomenda a literatura, inicialmente foi feita uma leitura flutuante para, posteriormente, fazer-se uma leitura mais minuciosa, a qual permitisse uma melhor compreensão das informações. Posteriormente procedeu-se a separação dos textos em categorias.

A análise de conteúdo é uma técnica que permite inferências sobre a organização do pensamento, através dos discursos, uma vez que se observa os textos de acordo com aquilo que estes apresentam. Bardin (2002), referindo-se à análise de conteúdo, sugere que esta trata de um conjunto de técnicas utilizadas para uma análise sistemática das comunicações. A ideia é obter-se indicadores que ajudem a interpretação dos conhecimentos das mensagens.

Para este trabalho, a análise do conteúdo serviu como forma de avaliar os artigos secundariamente, após feita inicialmente a seleção por meios dos títulos e/ou resumos. Foram também consideradas as citações nos textos, porque representam uma escolha dos autores quando da fundamentação dos seus discursos. Uma vez os textos organizados dessa maneira, pode-se estabelecer o corpus do trabalho.

Foram encontrados 47 artigos, dos quais 13 foram selecionados para compor essa revisão, por enquadrar-se nos critérios de inclusão, conforme fluxograma a seguir. 


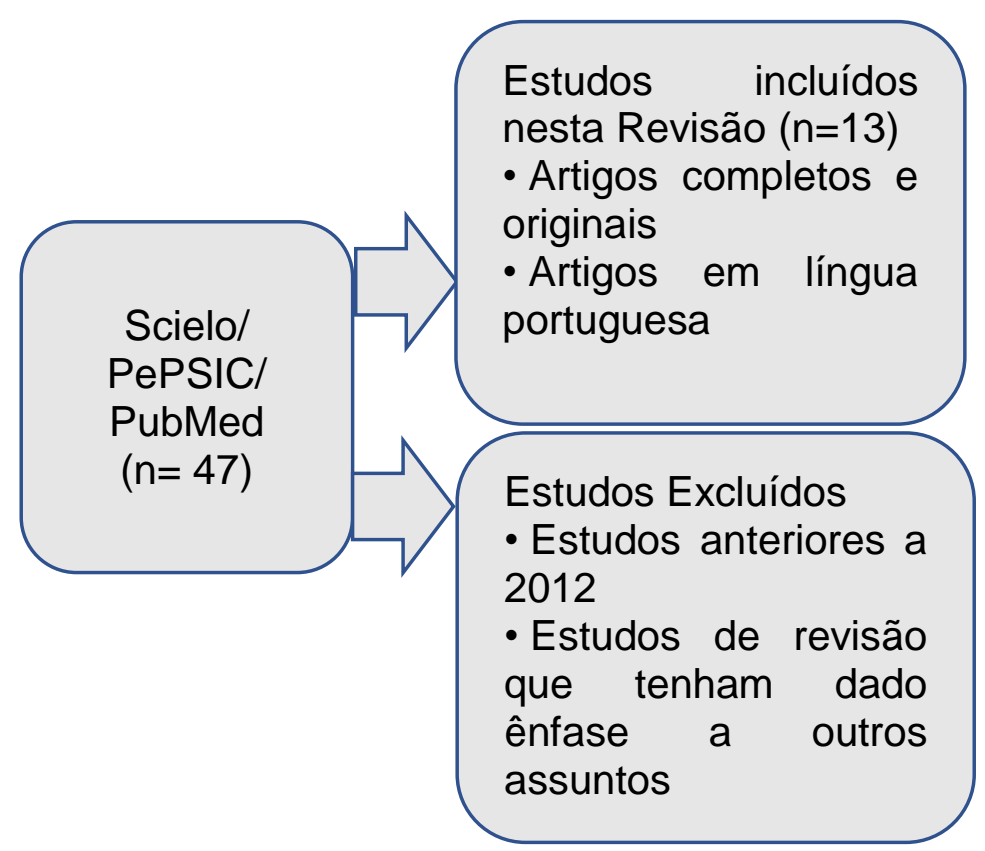

Figura 1: Fluxograma demonstrativo da seleção dos estudos

Tabela 1- Artigos selecionados para esse estudo

\begin{tabular}{|c|c|}
\hline Artigos & Categorias \\
\hline 1. SENNA e DESSEN, 2012 & 1 \\
\hline 2. QUIROGA e VITALLE, 2013 & 1 \\
\hline 3. VELHO, QUINTANA e ROSSI, 2014 & 1 \\
\hline 4. BECKER, BOBATO e SCHULZ, 2012 & 2 \\
\hline 5. MAGALHÃES, ALVARENGA e TEIXEIRA, 2012 & 2 \\
\hline 6. $\quad$ VALORE e CAVALLET, 2012 & 2 \\
\hline 7. COLOMBO e PRATI, 2014 & 2 \\
\hline 8. JUNQUEIRA e MELO-SILVA, 2014 & 2 \\
\hline 9. ANDRADE et al, 2016 & 2 \\
\hline 10. BARBOSA e LAMAS, 2012 & 3 \\
\hline 11. DUARTE, 2013 & 3 \\
\hline 12. FALEIROS e LEHMAN, 2013 & 3 \\
\hline 13. SANTOS, LUNA e BARDAGI, 2014 & 3 \\
\hline
\end{tabular}

Estão expostos na tabela acima os autores e os anos de publicação dos treze artigos selecionados. As informações na tabela estão organizadas das obras mais antigas as mais novas publicadas dentro de cada categoria, nesse caso em três. 


\section{Análise e Discussão}

Foram selecionados 13 artigos: cinco artigos foram publicados em 2012, três no ano de 2013, quatro no ano de 2014 e um referente ao ano de 2016. Foi identificado que referente ao ano de 2015 ocorreu uma ausência de publicações referente as temáticas abordadas neste trabalho, entretanto os anos de 2012 e 2014 tiveram maior número de publicações.

Sobre a quantidade de autores por artigo: um artigo foi produzido por um único autor, sete artigos foram produzidos por apenas dois autores, quatro artigos foram produzidos por três autores, e um artigo teve cinco autores, sendo este o que teve o maior número de autores.

Com relação a análise do tema, esta será feita através de uma separação em três categorias: 1- Adolescência; 2- Influências e escolha profissional; 3 - Orientação profissional como ferramenta de auxílio.

\section{Categoria 1 - Adolescência}

Tabela 2- Artigos que compõem a categoria 1 - Adolescência

\begin{tabular}{|c|c|c|c|}
\hline Autor & Titulo & Ano & Resultados \\
\hline SENNA e DESSEN & $\begin{array}{l}\text { Contribuições das Teorias do } \\
\text { Desenvolvimento Humano para } \\
\text { a Concepção contemporânea da } \\
\text { adolescência }\end{array}$ & 2012 & $\begin{array}{l}\text { A delimitação deste período } \\
\text { ultrapassa aspectos cronológicos e } \\
\text { biológicos e esbarra em condições } \\
\text { sociais, culturais, históricas e } \\
\text { psicológicas específicas. }\end{array}$ \\
\hline $\begin{array}{l}\text { QUIROGA } \\
\text { VITALLE }\end{array}$ & 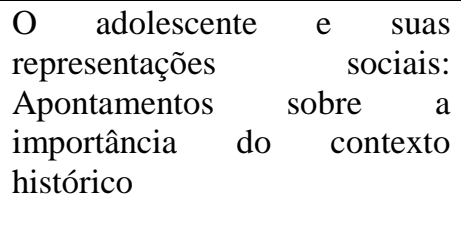 & 2013 & $\begin{array}{l}\text { O período da adolescência, antes } \\
\text { carente de referências e } \\
\text { representações sociais positivas, } \\
\text { quando visto sob uma perspectiva } \\
\text { mais hodierna, adquire seu próprio } \\
\text { escopo simbólico. }\end{array}$ \\
\hline $\begin{array}{l}\text { VELHO, } \\
\text { QUINTANA } \\
\text { ROSSI }\end{array}$ & $\begin{array}{l}\text { Adolescência, autonomia } \\
\text { pesquisa em Seres Humanos }\end{array}$ & 2014 & $\begin{array}{l}\text { Apontam estágios do } \\
\text { desenvolvimento moral às pessoas, } \\
\text { com o apropriado desenvolvimento } \\
\text { e discernimento moral que podem } \\
\text { ter os adolescentes para fazer suas } \\
\text { escolhas e administrar suas } \\
\text { consequências. }\end{array}$ \\
\hline
\end{tabular}

Fonte: Pesquisa própria

Esta categoria foi organizada com os artigos que discutem questões referentes a fase do desenvolvimento humano na adolescência. 
Com relação ao desenvolvimento humano no período da adolescência Senna e Dessen (2012) trazem a ideia de que o desenvolvimento do sujeito sofre influências de três elementos, o momento, a situação e o desenvolvimento, basicamente esse adolescente entra em contato com fatores intrínsecos e das questões atreladas as leis, finanças e dos hábitos e costumes da sociedade, do meio em que o mesmo está inserido, no intuito de alcançar a homeostase.

Complementando o posicionamento de Senna e Dessen (2012), Quiroga e Vitalle (2013) trazem a ideia de que esta fase do desenvolvimento marca o fim da vida infantil e prepara o sujeito par adentrar na vida adulta. No período da adolescência o indivíduo busca o autoconhecimento. O meio em que o mesmo está inserido e o fator genético influenciam nesse processo. Esta fase é marcada por inconsistências e alterações, na qual o sujeito vivencia questionamentos e momentos diferentes que causam dúvidas e incertezas.

Velho, Quintana e Rossi (2014) apontam que a fase da adolescência é constituída através do meio social e da cultura instaurada neste ambiente. $O$ desenvolvimento desta fase sofre influencias do fator econômico, pois acredita-se que a adolescência ocorre com mais frequência com sujeitos advindos de uma classe financeira mais favorável. Assim esses autores trazem a questão econômica como algo que proporciona um impacto relevante no desenvolvimento humano.

Com relação a durabilidade desta fase do desenvolvimento Velho, Quintana e Rossi (2014) expõem que o período da adolescência começa aos 10 anos e tem seu termino aos 19 . Nesse ponto, divergem de Senna e Dessen (2012), que trazem a ideia de que esta etapa não tem uma delimitação clara referente ao seu início e fim, já que a mesma é influenciada pelo meio em que este sujeito está engajado.

Segundo Senna e Dessen (2012), o indivíduo nessa fase possui sua subjetividade, desenvolve sua maneira de funcionamento frente as demandas do cotidiano, portando-se assim como alguém presente e engajado no processo de crescimento. Quiroga e Vitalle (2013) corroboram com tal pensamento, visto que estes autores acreditam que o adolescente passou de uma posição passiva, desenvolvendo assim uma postura participante frente a constituição de si e do seu meio.

Velho, Quintana e Rossi (2014) põem em questão a importância da obtenção da maturidade nesse período da adolescência, para que este sujeito possa compreender e fazer escolhas mais assertivas. De acordo com estes autores o adolescente, por volta dos 14 anos, já consegue compreender e executar escolhas referentes a seu bem-estar e o meio social. 
A respeito dos grupos sociais que o adolescente desenvolve vínculos, Senna e Dessen (2012) trazem a ideia de que a família ainda é caracterizada como a instituição mais importante no tocante ao desenvolvimento do sujeito. O núcleo familiar possui a função de transmitir as crenças e valores nutridos pelo respetivo grupo, além de exigir do sujeito uma flexibilidade onde este deve desempenhar diversas funções. Tais características exigidas buscam trabalhar o aprendizado e a comunicabilidade deste adolescente. No tocante ao grupo de amigos de acordo com os mesmos autores este proporciona interferências no desenvolvimento do indivíduo que está vivenciando a adolescência. Compreendendo as ideias de tais autores, Velho, Quintana e Rossi (2014) entendem que o núcleo familiar e as relações de amizade influenciam no processo de construção do sujeito.

Senna e Dessen (2012) lançam uma crítica referente a ideia de que ainda existe um determinismo atrelado a explicação da adolescência, sendo esta compreendida como um momento nebuloso envolto de problemas, atitudes impróprias e uma instabilidade emocional. Estes autores se propõem a compartilhar uma visão acerca desta fase pautada apenas em questões pessoais do sujeito, ou extinguir os fatores biológicos e sociais limita a visão daquele que busca estudar e compreender esta fase do desenvolvimento, criticando assim tal postura.

Segundo Senna e Dessen (2012) os estudos atuais referentes a esta temática defendem a ideia de que não se pode a limitar a um processo apenas de modificações, pois se acredita atualmente que este é um percurso linear no tocante ao desenvolvimento humano.

Quiroga e Vitalle (2013) compartilham do posicionamento trazido por Senna e Dessen (2012) na compreensão de que a fase da adolescência não pode continuar sendo descrita como algo temporário, já que o sujeito consegue identificar um espaço representativo próprio para este período. Velho, Quintana e Rossi (2014) partilham da visão de tais autores sobre que na sociedade atual esse período do desenvolvimento é caracterizado por uma construção em movimento que faz parte constituinte desse período. 
Categoria 2 - Influências e Escolha profissional

Tabela 3- Artigos que compõem a categoria 2 - Influencias e escolha profissional

\begin{tabular}{|c|c|c|c|}
\hline Autor & Titulo & Ano & Resultados \\
\hline $\begin{array}{l}\text { BECKER, BOBATO e } \\
\text { SCHULZ }\end{array}$ & $\begin{array}{l}\text { Meu lugar no mundo: } \\
\text { Relato de experiência } \\
\text { com jovens em } \\
\text { orientação profissional }\end{array}$ & 2012 & $\begin{array}{l}\text { Apontaram que os adolescentes } \\
\text { demonstraram expectativas positivas } \\
\text { em relação ao futuro e à sua carreira } \\
\text { profissional. }\end{array}$ \\
\hline $\begin{array}{l}\text { MAGALHÃES, } \\
\text { ALVARENGA e } \\
\text { TEIXEIRA }\end{array}$ & $\begin{array}{l}\text { Relação entre estilos } \\
\text { parentais, instabilidade } \\
\text { de metas e indecisão } \\
\text { vocacional } \\
\text { adolescentes }\end{array}$ & 2012 & $\begin{array}{l}\text { Os estilos parentais influenciam no } \\
\text { desenvolvimento de recursos } \\
\text { fundamentais de personalidade, tais } \\
\text { como a capacidade de estabelecer e } \\
\text { manter metas, que por sua vez tem } \\
\text { impacto em variáveis do } \\
\text { desenvolvimento vocacional como a } \\
\text { decisão de carreira. }\end{array}$ \\
\hline $\begin{array}{l}\text { VALORE e } \\
\text { CAVALLET }\end{array}$ & $\begin{array}{l}\text { Escolha e Orientação } \\
\text { Profissional de } \\
\text { estudantes de curso pré- } \\
\text { vestibular popular }\end{array}$ & 2012 & $\begin{array}{l}\text { Embora o aspecto econômico não tenha } \\
\text { sido apontado como critério ou } \\
\text { dificuldade principal da escolha } \\
\text { profissional, os resultados encontrados } \\
\text { corroboraram outros dados da literatura, } \\
\text { evidenciando sua influência e indicando } \\
\text { a necessidade de avanços nesse sentido. }\end{array}$ \\
\hline COLOMBO e PRATI & $\begin{array}{l}\text { Maturidade para } \\
\text { escolha profissional, } \\
\text { habilidades sociais e } \\
\text { inserção no mercado de } \\
\text { trabalho }\end{array}$ & 2014 & $\begin{array}{l}\text { As habilidades sociais e } \mathrm{e} \\
\text { trabalho na juventude são aspectos } \\
\text { importantes para o desenvolvimento da } \\
\text { maturidade de carreira, devendo ser } \\
\text { considerados nas intervenções de } \\
\text { orientação profissional. }\end{array}$ \\
\hline $\begin{array}{l}\text { JUNQUEIRA e } \\
\text { MELO-SILVA }\end{array}$ & $\begin{array}{lrr}\text { Maturidade } & \text { para a } \\
\text { escolha de } & \text { carreira: } \\
\text { estudo } & \text { com } \\
\text { adolescentes de } & \text { um } \\
\text { serviço-escola } & & \\
\end{array}$ & 2014 & $\begin{array}{l}\text { Os adolescentes chegam necessitando } \\
\text { principalmente desenvolver o } \\
\text { autoconhecimento e o conhecimento da } \\
\text { realidade para adquirirem competências } \\
\text { para a tomada de uma decisão madura. }\end{array}$ \\
\hline ANDRADE et al & $\begin{array}{l}\text { Adolescência, Escolha } \\
\text { Profissional } \quad \text { e } \\
\text { Identificação: Uma } \\
\text { Revisão Sistemática }\end{array}$ & 2016 & $\begin{array}{l}\text { Os fatores elencados foram: políticos, } \\
\text { sociais, culturais, tecnológicos, } \\
\text { econômicos, educacionais, individuais, } \\
\text { psicológicos e familiares; sendo } \\
\text { destacados nas produções científicas os } \\
\text { fatores familiares a a relação com os } \\
\text { pares, no que se refere aos fatores } \\
\text { psicológicos. }\end{array}$ \\
\hline
\end{tabular}

Fonte: Pesquisa própria.

Foram agrupados nesta categoria os artigos que discursam sobre as influencias e os fatores que afetam a escolha profissional no período da adolescência.

Se tratando do momento da escolha na adolescência Andrade et al (2016) elenca que o sujeito faz diversas escolhas ao longo da vida, no entanto, a escolha de uma profissão na 
adolescência é algo delicado e importante, tendo em vista os demais conflitos e questionamentos que esse sujeito enfrente nesta fase do desenvolvimento.

Colombo e Prati (2014) expõem que a maturidade é algo de suma relevância, tendo em vista que a mesma constitui a identidade do sujeito, e que é fundamental no momento da escolha profissional. Para que o indivíduo possa exercer uma boa escolha ele deve estar preparado para tomar decisões e elencar escolhas, assim para que este adolescente escolha uma profissão ele deve se autoconhecer e ter capacidade de compreender as consequências de suas escolhas.

De acordo com os resultados encontrados na pesquisa feita por Colombo e Prati (2014) demonstram que o grau de desenvolvimento da maturidade pode crescer se o indivíduo participar do desenvolvimento de orientação profissional, e que a atuação do adolescente no mundo do trabalho atrelada ao seu desempenho e desenvoltura social influenciam no desenrolar dessa característica tão necessária. Junqueira e Melo-Silva (2014) citam dois fatores que compõem o desenvolvimento de tal característica, são aspectos emocionais e intelectuais, compartilhando com o posicionamento trazido por Colombo e Prati (2014).

O estudo feito por Junqueira e Melo-Silva (2014) elenca três aspectos que devem ser trabalhados e desenvolvido nos adolescentes que irão exercer a escolha de uma profissão, são estas, obstinação, compreensão do ambiente em que está inserido e de si mesmo.

Becker, Bobato e Schulz (2012) elencam dois pontos necessários para que o sujeito faça uma escolha profissional assertiva. Primeiramente é de suma importância que o adolescente tenha autoconhecimento, reconhecendo seus pontos portes e frágeis. E em segundo lugar é necessário que este sujeito reconheça o quanto o meio em que está inserido interfere em sua escolha profissional.

Colombo e Prati (2014) ressaltam que o meio em que o indivíduo se insere influenciam na constituição da personalidade profissional e pessoal, concordando assim com a ideia trazida por Becker, Bobato e Schulz (2012) referente ao ambiente.

Colombo e Prati (2014) citam como alguns dos aspectos que interferem na constituição da subjetividade e na decisão profissional que esse sujeito tem que fazer são a escola e a mídia. Já Andrade et al (2016) elencam alguns fatores influentes na escolha profissional, sendo estes, financeiros, culturais e subjetivos, entre outros.

Baseado na pesquisa feita por Valore e Cavallet (2012) o fator financeiro não foi trazido como um dos determinantes na escolha profissional, entretanto baseado no que foi elencado por 
esses autores e baseando-se em estudos recentes esse fator possui um forte impacto na escolha dos adolescentes.

Junqueira e Melo-Silva (2014) concordam com Becker, Bobato e Schulz (2012) e Colombo e Prati (2014) e Colombo e Prati (2014) no tocante ao reconhecimento das influencias. No entanto, Junqueira e Melo-Silva (2014) buscam focar na ideia de que tais fatores impactam no momento escolha profissional, mas que o mais importante é que o adolescente consiga distinguir aquilo que é relevante ou não, para que este possa tomar decisões.

Becker, Bobato e Schulz (2012) e Colombo e Prati (2014) e Andrade et al (2016) no tocante ao reconhecimento das influencias. No que se refere as influencias no momento da tomada de decisão referente a profissão, de acordo com Becker, Bobato e Schulz (2012) entre todos os fatores dois se sobressaem a mídia e o núcleo familiar. Estes autores relatam que o grupo familiar é que possui um peso maior no momento da decisão do adolescente, tendo em mente que a aprovação dos pais é importante para o adolescente que faz essa escolha. Magalhães, Alvarenga e Teixeira (2012) trazem que o ambiente familiar é a instituição que se mostra com mais força impactando a escolha profissional do adolescente, compartilhando assim a ideia apontada por estes autores.

Magalhães, Alvarenga e Teixeira (2012) trazem que os estilos parentais influenciam na constituição da personalidade quanto referente a escolha profissional, e para que o adolescente possa executar essa escolha com mais eficácia é necessário que haja entre o adolescente e sua família uma relação de afeto, onde ocorra o afastamento entre as figuras parentais e o mesmo, para que este possa crescer.

De acordo com Magalhães, Alvarenga e Teixeira (2012) o grupo familiar, o autoconhecimento e o processo de escolha profissional estão relacionados, já que para o indivíduo exercer sua escolha este deve possuir uma relação saldável com seus pais, assim, o mesmo possa buscar construir sua subjetividade, e finalmente tomar a decisão de qual profissão deve seguir.

Torna-se relevante ressaltar que na pesquisa efetuada por Magalhães, Alvarenga e Teixeira (2012) os adolescentes que possuem pais que exercem o estilo parental autoritário expressaram um maior impedimento no tocante a escolha de uma carreira, tendo em vista que este sujeito mostrou passar por complicações referentes à constituição da subjetividade e autoconhecimento. 
Valore e Cavallet (2012) evidenciam que o fator econômico está cada vez mais influenciando na escolha profissional dos adolescentes, tendo em vista que é necessário que estes sujeitos identifiquem e compreendam a realidade social em que se encontram para que posteriormente possa ser traçado um plano de ação, onde serão elencados objetivos no qual estes devem buscar alcançar. Assim estes autores buscam dar um foco maior ao status financeiro como um dos fatores que mais influencia a escolha profissional, diferente de Becker, Bobato e Schulz (2012) e Magalhães, Alvarenga e Teixeira (2012) que trazer a questão familiar como principal fator.

Valore e Cavallet (2012) relatam que pesquisas recentes evidenciam que escassez de matérias informativos referentes as profissões e as possibilidades de aprimoramento profissional estão atreladas as condições financeiras, tendo em vista que estas podem influenciar negativamente os adolescentes advindos de uma faixa econômica menos favorecida, sendo assim estes indivíduos vivenciam uma relação desfavorecida, ao não possuir contato com algumas oportunidades.

Becker, Bobato e Schulz (2012) relatam que os participantes do seu trabalho possuem uma perspectiva otimista referente ao mundo do trabalho. Ao juntar as pesquisas feitas por Becker, Bobato e Schulz (2012) e Valore e Cavallet (2012) percebe-se que os adolescentes mesmo buscando adentrar no mundo das profissões se este sujeito não possuir incentivos ou fatores que impulsionem, essa escolha torna-se cada vez mais difícil de ser realizada.

\section{Categoria 3 - Orientação profissional como ferramenta de auxilio}

Tabela 4 - Artigos que compõem a categoria 3 - Orientação profissional como ferramenta de auxilio

\begin{tabular}{l|l|l|l}
\hline Autor & Titulo & Ano & Resultados \\
\hline BARBOSA e & $\begin{array}{l}\text { A orientação } \\
\text { profissional como } \\
\text { atividade transversal ao } \\
\text { currículo escolar }\end{array}$ & 2012 & $\begin{array}{l}\text { Os resultados relativos à quantidade de } \\
\text { professores que passaram a inserir o } \\
\text { trabalho e a escolha profissional de forma } \\
\text { transversal ao currículo pós-orientação } \\
\text { sugerem que, de modo geral, os objetivos } \\
\text { dessa atividade foram atingidos, isto é, } \\
\text { houve transversalização. }\end{array}$ \\
\hline DUARTE & $\begin{array}{l}\text { A vida da orientação na } \\
\text { vida do século XXI: } \\
\text { constrangimentos e endreira, enquanto } \\
\text { desafios }\end{array}$ & $\begin{array}{l}\text { O desenvolvimento da carreina } \\
\text { caminho linear e previsível, dá lugar à } \\
\text { individualização, ou seja, dá lugar à história } \\
\text { de cada um. A vida da orientação na vida do } \\
\text { século XXI exige uma certa antecipação do } \\
\text { futuro, mas é da responsabilidade de quem }\end{array}$ \\
\hline
\end{tabular}




\begin{tabular}{|c|c|c|c|}
\hline & & & $\begin{array}{l}\text { lida com o outro colocar nesse futuro a } \\
\text { esperança como fazendo parte do caminho. }\end{array}$ \\
\hline $\begin{array}{l}\text { FALEIROS e } \\
\text { LEHMAN }\end{array}$ & $\begin{array}{lr}\text { Imbricações } & \text { históricas } \\
\text { e problemas práticos } \\
\text { em orientação } \\
\text { profissional r no } \\
\text { contexto escolar }\end{array}$ & 2013 & $\begin{array}{l}\text { Apesar de a escola ser demandada a criar } \\
\text { estratégias no âmbito da preparação para a } \\
\text { cidadania e trabalho, é perceptível que a } \\
\text { mesma caminha na via contrária, relegando } \\
\text { a orientação profissional a um lugar } \\
\text { secundário, desvinculado de seu cotidiano. }\end{array}$ \\
\hline $\begin{array}{l}\text { SANTOS, LUNA e } \\
\text { BARDAGI }\end{array}$ & \begin{tabular}{lr}
\multicolumn{2}{l}{ O desafio da orientação } \\
profissional com \\
adolescentes no \\
contexto & no \\
modernidade líquida & \\
\end{tabular} & 2014 & $\begin{array}{l}\text { Os impactos das características da } \\
\text { modernidade líquida nos processos de } \\
\text { orientação profissional correspondem a } \\
\text { uma temática praticamente inexplorada na } \\
\text { literatura. }\end{array}$ \\
\hline
\end{tabular}

Fonte: Pesquisa própria.

É esperado de acordo com Barbosa e Lamas (2012) que no decorrer do processo de orientação profissional, o orientador busque quebrar paradigmas e prejulgamentos que foram implantados pela propagação da comunicação, cultura e aqueles no qual o adolescente se relaciona. Tal ação possui o intuito de desconstruir ideias ilusórias que poderão causar algum impacto prejudicial na escolha profissional, tentando diminuir as contradições existentes no meio social, para que este adolescente possa desenvolver uma visão coesa e clara de realidade em que vive. Santos, Luna e Bardagi (2014) complementam essa ideia, pois eles acreditam que a orientação profissional pode facilitar a formação de uma postura reflexiva e cidadã, que irá proporcionar uma reflexão sobre o que este indivíduo espera do futuro e em como a sociedade atual influência nas suas ações, no intuito de que o mesmo consiga elencar e eleger prioridades que irão influenciar nas tomadas de decisões que este irá enfrentar nesse percurso profissional.

Barbosa e Lamas (2012) trazem que o ato de optar por um curso de nível superior ainda é algo bastante presente no discurso dos adolescentes, mesmo aqueles que advém de uma classe econômica menos favorável. Entretanto, muitos desses indivíduos não conseguem adentrar em um curso de nível superior. Assim, o profissional que atua na área de orientação profissional com adolescentes deve buscar incentivar o esse sujeito a procurar carreiras que não dependam diretamente de um curso de nível superior. Duarte (2013) reflete acerca da orientação profissional na atualidade, pontuando que esta busca deve assim proporcionar ao sujeito um desenvolvimento do aspecto profissional e do individual. 
Para que haja um bom desenvolvimento do processo de OP, Barbosa e Lamas (2012) relatam que o profissional identifique e compreenda o contexto social, potencialidades, fragilidades, perspectiva de desenvolvimento profissional e os princípios morais desse adolescente. Para que o orientador possa facilitar o processo, no intuito de que o orientando consiga reconhecer os fatores que impactam no momento de tomada de decisão recente a uma profissão.

Compreende-se assim que Barbosa e Lamas (2012) e Duarte (2013) compartilham da visão de que a orientação profissional é um processo de coprodução entre o orientador e o participante do processo de OP.

Barbosa e Lamas (2012) e Santos, Luna e Bardagi (2014) dividem o mesmo posicionamento no que se trata a OP com adolescentes. No que condiz essa perspectiva essa atividade busca autoconhecimento, modificando o modo como este sujeito se percebe e compreende o mundo a sua volta, possibilitando que o mesmo busque promover mudança partir de uma postura ativa.

Barbosa e Lamas (2012) trazem que a orientação profissional pode proporcionar diversos benefícios inserida no ambiente educacional. O processo de orientação profissional deveria ser desenvolvido no ambiente escolar, tendo em vista que os professores deveriam exercer uma posição dinâmica e executar atividades dirigidas ao mundo profissional, tornando a orientação profissional algo que perpassa todo o ambiente escolar.

Com base no estudo feito por Barbosa e Lamas (2012) quando a orientação profissional ocorre dentro do ambiente escolar, os professores para de exercer uma posição mais clássica e desenvolvem um trabalho onde propagam seus conhecimentos para os adolescentes, fazendo com que estes indivíduos assimilem aquilo que é ministrado em sala de aula a execução de uma atividade laboral.

Faleiros e Lehman (2013) discursam a respeito do ambiente escolar e a relação que este pode desenvolver com a orientação profissional. Estes autores relatam que é esperado que no ambiente escolar sejam discutidos temas relacionados ao mundo das profissões e a formação de uma postura ativa. No entanto existem divergências entre a orientação profissional nas escolas públicas e privadas. É exposto que o desenvolvimento da OP em uma escola pública não recebe tanta atenção e acaba focando apenas na propagação de conhecimento.

É importante ressaltar que Barbosa e Lamas (2012) e Faleiros e Lehman (2013) trazem duas visões referentes a orientação profissional no ambiente escolar, onde uma esboça os pontos 
positivos que o processo de OP pode oferecer e outra que expõe que essa ativada pode não ser bem executada se não tiver espaço para ser aplicada.

\section{Considerações Finais}

O presente estudo tinha como objetivo investigar acerca do desenvolvimento humano na fase da adolescência, e identificar os fatores que influenciam no momento da escolha profissional e de que modo a orientação profissional pode auxiliar esse sujeito no decorrer do processo de escolha de uma carreira.

Com relação a adolescência percebeu-se que esta fase ainda é considerada um período marcada por problemas e revoltas, propagando uma visão que não corresponde mais com o momento atual, ainda não há um consenso no que diz respeito da idade para que inicie e finalizar esta fase. Os aspectos biológicos, sociais, subjetivos, culturais, econômicos e familiares influenciam tanto o desenvolvimento do adolescente quanto as escolhas que este sujeito faz ao longo do percurso de sua vida, sendo uma destas a escolha profissional.

A metodologia utilizada para que o objetivo do trabalho fosse alcançado, foi a revisão sistemática por metassíntese. Neste estudo foi feita uma explanação referente ao desenvolvimento na fase da adolescência onde foram elencados e previamente explicados o desenvolvimento biológico, cognitivo, social e psicológico do indivíduo. Também foram investigados os aspectos necessários para que o adolescente pudesse exercer uma boa escola e quais fatores influenciam nessa decisão e de que maneira a orientação profissional poderia oferecer subsídios para auxiliar nesse processo.

A temática da adolescência e a escolha profissional, proporcionou uma visão mais ampla e a compreensão da necessidade de mais estudos, pois a aplicabilidade da orientação profissional mesmo crescente no contexto brasileiro ainda é algo muito simplório, evidenciando a necessidade de pesquisas e intervenções nessa área.

Observou-se que no processo de orientação profissional o adolescente deve desenvolver uma postura ativa e participante, trabalhar o autoconhecimento e a maturidade para exercer escolhas e tomar decisões. Contudo a ausência de artigos atuais que discutissem a respeito do desenvolvimento na fase da adolescência e de que maneira a orientação pode ser desenvolvida com este público foram as dificuldades mais relevantes que este estudo enfrentou. 
Os resultados proporcionados por este estudo oferecem uma reflexão no que se refere ao desenvolvimento da fase da adolescência, expondo que esta é composta por vários aspectos, não apenas os genéticos, pois o sujeito possui uma subjetividade e está inserido em um meio social. Possibilitou, ainda, uma compreensão de quais fatores influenciam na escolha de uma profissional e de que modo o ambiente escolar pode atrelar suas práticas as da orientação profissional no intuito de proporcionar ferramentas para que o sujeito possa tornar-se mais reflexivo, exercendo suas escolhas de modo mais crítico.

É importante ressaltar que mesmo que essa temática é muito rica, deixando assim, ainda um amplo espaço para o desenvolvimento de outros trabalhos, pois nem todas as obras encontradas nas bases de dados supriam todos os aspectos relacionados ao estudo.

\section{Referências}

ANDRADE, M. M.; MARANHÃO, T. L. G.; BARBOSA, J. S.; BATISTA, H. M. T.; SANTANA, A. O. Adolescência, Escolha Profissional e Identificação: Uma Revisão Sistemática. Id on Line Rev. Psic. V.10, N. 30. Supl 3, Julho/2016. Disponível em <http://idonline.emnuvens.com.br/id> Acesso em 29 de setembro de 2016.

BARBOSA, A. J. G.; LAMAS, K. C. A. A Orientação Profissional Como Atividade transversal ao currículo escolar. Estud. psicol. (Natal), Natal, v. 17, n. 3, p. 461-468, dezembro de 2012. Disponível em <http://www.scielo.br/scielo.php?script=sci_arttext\&pid=S1413294X2012000300015\&lng=en\&nrm=iso>. Acesso em 11 de outubro de 2016.

BARDIN, Laurence. Análise de conteúdo. Lisboa: Edições 70, 2002

BECKER, A. P. S.; BOBATO, S. T.; SCHULZ, ,. L. C. Meu lugar no mundo: Relato de experiência com jovens em orientação profissional. Rev. bras. orientac. prof, São Paulo, v. 13, n. 2, p. 253-264, dez. $2012 \quad$. $\quad$ Disponível <http://pepsic.bvsalud.org/scielo.php?script=sci_arttext\&pid=S1679-

$33902012000200012 \& \operatorname{lng}=$ t\&nrm=iso > . Acesso em 25 de setembro de 2016.

BERGER, K. S. O desenvolvimento da pessoa: da infância à terceira idade. 5. ed. Rio de Janeiro: LTC, 2013.

COLOMBO, G.; PRATI, L. E. Maturidade para escolha profissional, habilidades sociais e inserção no mercado de trabalho. Rev. bras. orientac. prof, São Paulo , v. 15, n. 2, p. 2012014 . dez.
$<$ http://pepsic.bvsalud.org/scielo.php?script=sci arttext\&pid=S1679-

$33902014000200010 \& \operatorname{lng}=$ pt\&nrm=iso $>$. Acesso em 22 de setembro de 2016. 
DIAS, D,; SA, M. J. O estatuto sociocultural familiar como vetor da decisão vocacional: promessas e (des)ilusões da entrada na educação superior. Rev. bras. orientac. prof, São Paulo , v. 15, n. 1, p. 51-64, jun. 2014 . Disponível em $<$ http://pepsic.bvsalud.org/scielo.php?script=sci_arttext\&pid=S1679-

$33902014000100007 \& \operatorname{lng}=$ pt\&nrm=iso>. Acesso em 27 de setembro de 2016.

DIGIÁCOMO, M. J.; DIGIÁCOMO, I. A. Estatuto da criança e do adolescente: anotado e interpretado. 6 ed. Centro de Apoio Operacional das Promotorias da Criança e do Adolescente. Curitiba: Ministério Público do Estado do Paraná, 2013. Disponível em: http://www.planalto.gov.br/ccivil_03/leis/18069.htm, v. 15, 2013. Acesso em 04 de setembro de 2016.

DUARTE, M. E. A vida da orientação na vida do século XXI: constrangimentos e desafios. Rev. bras. orientac. prof, São Paulo , v. 14, n. 2, p. 155164, dez. 2013. Disponível em $<$ http://pepsic.bvsalud.org/scielo.php?script=sci_arttext\&pid=S1679-

$33902013000200002 \& \operatorname{lng}=$ pt\&nrm=iso $>$. Acesso em 04 de setembro de 2016.

FERRONHA, J.; ALMEIDA, A.; OLIVEIRA, L.; SOUSA, J. T.; SOUSA, V. Estudo da Vinculação e da Empatia em Adolescentes Institucionalizados com Acompanhamento Psicológico no PIAC (Plano Integrado de Apoio à Comunidade). International Journal of Developmental and Educational Psychology INFAD, Revista de Psicologia, v.1, n.1, p. 327 338, 2014. ISSN: 0214-9877. $\quad$ Disponível em <http://www.infad.eu/RevistaINFAD/OJS/index.php/IJODAEP/article/view/378>. Acesso em 09 de outubro 2016.

GALVÃO, T, F.; PEREIRA, M, G.; Revisões sistemáticas da literatura: passos para sua elaboração. Epidemiologia e Serviço de Saúde, v.23, n.1, Brasília (2014). Disponível em: <http://scielo.iec.pa.gov.br/scielo.php?pid=S167949742014000100018\&script=sci_arttex t\&tlng=es> Acesso em 29 de setembro de 2016.

GUICHARD, J. Quais os desafios para o aconselhamento em orientação no início do século 21?. Rev. bras. orientac. prof, São Paulo, v. 13, n. 2, p. 139-152, dez. 2012. Disponível em $<$ http://pepsic.bvsalud.org/scielo.php?script=sci_arttext\&pid=S1679-

$33902012000200002 \& \operatorname{lng}=$ pt\&nrm=iso $>$. Acesso em 04 de setembro de 2016.

JUNQUEIRA, M. L.; MELO-SILVA, L. L. Maturidade para a escolha de carreira: estudo com adolescentes de um serviço-escola. Rev. bras. orientac. prof, São Paulo , v. 15, n. 2, p. 187199, dez. $2014 \quad$. 2 Disponível em $<$ http://pepsic.bvsalud.org/scielo.php?script=sci_arttext\&pid=S1679$33902014000200009 \& \operatorname{lng}=$ pt\&nrm=iso>. Acesso em 09 outubro 2016.

MAGAlHAES, M. O; ALVARENGA, P.; TEIXEIRA, M. A. P. Relação entre estilos parentais, instabilidade de metas e indecisão vocacional em adolescentes. Rev. bras. orientac. prof, São Paulo , v. 13, n. 1, p. 15-25, jun. 2012.. Disponível em 
$<$ http://pepsic.bvsalud.org/scielo.php?script=sci_arttext\&pid=S1679-

$33902012000100004 \& \operatorname{lng}=$ pt\&nrm=iso>. Acesso em 17 de setembro de 2016.

MANAIA, M. M. C. et al. Carta aos pais: uma estratégia de comunicação dos filhos sobre a escolha da carreira. Rev. SPAGESP, Ribeirão Preto, v. 14, n. 2, p. 19-38, 2013. Disponível em <http://pepsic.bvsalud.org/scielo.php?script=sci_arttext\&pid=S1677$29702013000200003 \& \operatorname{lng}=$ pt\&nrm=iso>. Acesso em 04 de setembro de 2016.

NEIVA, K. M. C. Processos de escolha e orientação profissional. -2. Ed.- Campinas, SP: editora Alínea, 2013.

NERY, J. C. S.; RUEDA, F. J. M. Capacidade preditiva do raciocínio visuoespacial no interesse e na escolha profissional. Rev. bras. orientac. prof, São Paulo , v. 14, n. 2, p. 255264, dez. 2013.. Disponível

$<$ http://pepsic.bvsalud.org/scielo.php?script=sci_arttext\&pid=S1679-

33902013000200010\&lng=pt\&nrm=iso>. Acesso em 04 de setembro de 2016.

OLIVEIRA, G. F.; Batista, H. M. T.; David de Oliveira Rufato, D. O.; Maranhão, T. L. G.; Braga, I. B.; Guedes, J. D. Psicologia do trânsito: uma revisão sistemática. Cad. Cult. Ciênc. Ano IX, v.13 n.2, Mar, 2015. Disponível em <http://periodicos.urca.br/ojs/index.php/cadernos/article/view/850/pdf_1> Acesso em 20 de setembro de 2016.

OLIVEIRA, M. C.; MELO-SILVA, L. L; COLETA, M. F. D. Pressupostos teóricos de super: datados ou aplicáveis à psicologia vocacional contemporânea? Rev. bras. orientac. prof, São Paulo , v. 13, n. 2, p. 223-234, dez. 2012. Disponível em $<$ http://pepsic.bvsalud.org/scielo.php?script=sci_arttext\&pid=S1679-

33902012000200009\&lng=pt\&nrm=iso>. Acesso em 04 de setembro de 2016.

PAPALIA, D. E. e FELDMAN, R. D. Desenvolvimento humano. 12. ed. Porto Alegre: AMGH, 2013.

QUIROGA, F. L.; VITALLE, M. S. S. O adolescente e SUAS Representações Sociais: Apontamentos Sobre a importância do contexto histórico. Physis , Rio de Janeiro, v 23, n.. 3, p. 863-878, setembro de 2013 . Disponível <http://www.scielo.br/scielo.php?script=sci_arttext\&pid=S0103-

$73312013000300011 \& \operatorname{lng}=$ en\&nrm=iso >. Acesso em 12 de setembro de 2016.

SANTOS, M. M.; LUNA, I. N; BARDAGI, M. P. O desafio da orientação profissional com adolescentes no contexto da modernidade líquida. Revista de Ciências Humanas, Florianópolis, v. 48, n. 2, p. 303, dez. 2014. ISSN 2178-4582. Disponível em: $<$ https://periodicos.ufsc.br/index.php/revistacfh/article/view/2178-

4582.2014v48n2p303/28513>. Acesso em 12 de setembro de 2016.

SENNA, S. R. C. M.; DESSEN, M. A. Contribuições das Teorias do Desenvolvimento Humano parágrafo A Concepção contemporânea da adolescência. Psic .: Teor. e Pesq. , Brasília, v. 28, n. $1, \quad$ p. 101-108, março de 2012. Disponível em 
<http://www.scielo.br/scielo.php?script=sci_arttext\&pid=S0102-

$37722012000100013 \& \operatorname{lng}=\mathrm{en} \& \mathrm{nrm}=\mathrm{iso}>$. Acesso em 12 de setembro de 2016.

VALORE, L. A.; CAVALLET, L. H. R.. Escolha e Orientação Profissional de Estudantes de curso pré-vestibular popular. Psicol. Soc. , Belo Horizonte, v. 24, n. 2, p. 354-363, agosto de 2012. Disponível a partir <http://www.scielo.br/scielo.php?script=sci_arttext\&pid=S0102$71822012000200013 \& \operatorname{lng}=e n \& n r m=i s o>$. Acesso em 04 de setembro de 2016.

VELHO, M. T. A. de C.; QUINTANA, A. M.; ROSSI, A. G. Adolescência, autonomia e pesquisa em Seres Humanos. Rev. Bioét. , Brasília, v. 22, n. 1, p. 76-84, abril de 2014. Disponível em <http://www.scielo.br/scielo.php?script=sci_arttext\&pid=S1983$80422014000100009 \& \operatorname{lng}=\mathrm{en} \& \mathrm{nrm}=\mathrm{iso}>$. Acesso em 12 de setembro de 2016.

\section{Como citar este artigo (Formato ABNT):}

LIMA, Maria Nayara Bezerra; MARANHÃO, Thércia Lucena Grangeiro. Orientação Profissional na Adolescência : Uma Revisão Sistemática. Id on Line Rev.Mult. Psic., 2018, vol.12, n.42, p. 158-186. ISSN: 1981-1179.

Recebido: 24/08/2018;

Aceito: $27 / 08 / 2018$ 